\title{
Innovation-oriented dynamic capabilities of logistics service providers, dynamic resilience and firm performance during the COVID-19 pandemic
}

\author{
Irina Dovbischuk \\ IU International University of Applied Sciences, Bremen, Germany
}

Dynamic

resilience

capabilities

Received 30 January 2021

Revised 9 June 2021

4 October 2021

Accepted 17 November 2021

\begin{abstract}
Purpose - The purpose of this paper is to use a theoretical framework to investigate the relationships between different innovation-oriented dynamic capabilities, dynamic resilience and firm performance among logistics service providers (LSPs) and in-house logistics departments of industrial companies during the coronavirus disease 2019 (COVID-19) pandemic.

Design/methodology/approach - The conceptual theoretical framework relies on the dynamic capabilities framework (DCF) and the relational view (RV), which are rooted in the resource-based view (RBV). It is hypothesized that the dynamic capability to innovate reinforces the dynamic capability to adapt and to recover in highly dynamic and vulnerable environments during the pandemic. This allows LSPs to successfully create new services and respond to the changing market circumstances in terms of logistics service quality (LSQ) and firm performance. Data were collected from 83 LSPs and 30 in-house logistics departments via an online survey. The study determined the general strength and direction of the relationships between latent variables. A correlation analysis was utilized to establish statistical significance of the results.

Findings - In this study, a range of innovation-oriented capabilities for achieving more dynamic resilience were bundled in a conceptual framework and were found to be statistically significant for LSQ and firm performance. They are the capability to distribute new knowledge, to train employees effectively, to develop cross-functional collaboration within the firm, to develop inter-firm relationships with business partners on a long-term basis as well as to learn from rivals, and to pursue a win-win relationship with them.

Research limitations/implications - The results of the study do not imply that the identified capabilities are the only ones relevant to increasing dynamic resilience during the pandemic. In October 2020, the COVID-19 pandemic was at different stages in different countries, so that the level to which firms were affected varied, and although the data were collected during one month only, due to the high dynamics of the pandemic, data were collected during different stages of disruptions, even among respondents in the same country. This study was set in the context of COVID-19, and it could not be proved whether the conceptual framework is generalizable to other crises or particular industries, but it would be worthwhile to examine this in the future. Finally, it was not tested whether LSQ mediates the relationship between innovative capabilities and firm performance during the pandemic.

Practical implications - The results help managers with regard to their strategic and operational decisions in relation with COVID-19. These findings are useful for executives and logistics managers to improve these capabilities to gain a competitive advantage during pandemic and to find their strengths and weaknesses to
\end{abstract}

(C) Irina Dovbischuk. Published by Emerald Publishing Limited. This article is published under the Creative Commons Attribution (CC BY 4.0) licence. Anyone may reproduce, distribute, translate and create derivative works of this article (for both commercial and non-commercial purposes), subject to full attribution to the original publication and authors. The full terms of this licence may be seen at http:// creativecommons.org/licences/by/4.0/legalcode

This paper forms part of a special section "Resilient supply chains through innovative logistics management", guest edited by Peggy S. Chen and Jiangang Fei.

The author would like to thank two anonymous reviewers for their invaluable suggestions which helped to improve the manuscript immensely and Waqas Ali for his help with the data collection for this research.

Open Access publication enabled by IU International University of Applied Sciences.

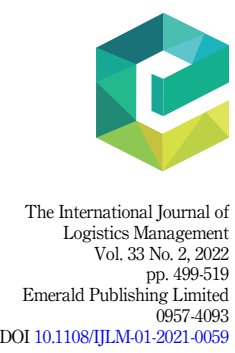


IJLM 33,2

develop critical capabilities for situations with a high turbulence and dynamic in their environment, and therefore provide a path for improvement.

Originality/value - This paper operationalizes a multi-theoretical conceptual framework in the context of logistics management (LM) and supply chain management (SCM). This conceptual framework was empirically tested.

Keywords COVID-19, Dynamic capabilities framework, Firm performance, Innovation, Logistics service providers, Relational view, Resilience

Paper type Research paper

\section{Introduction}

The coronavirus disease 2019 (COVID-19) pandemic has been hitting the business world at an unprecedented scale and speed (International Monetary Fund, 2020; Choi et al., 2020; Ivanov and Dolgui, 2020): the stoppages of factory outputs, the closures of business and the disruptions to global supply networks occurred first in China and affected global supply chains across the whole world at the beginning of 2020. As a result of the multiple waves of the COVID-19 pandemic, many original equipment manufacturers in different industries and their corresponding supply networks are suffering from permanent unpredictable disruptions. The pandemic reminded the business decision-makers of the importance of widening firm performance measures to include resilience, responsiveness and reconfigurability (Betti and $\mathrm{Ni}, 2020$ ). The COVID-19 pandemic underlined not only the weaknesses of global supply chains that are trimmed for efficiency, minimized inventory, lean manufacturing or single sourcing strategies (Lin and Lanng, 2020) but also the importance of the resilience concept (Choi et al., 2020) and of innovative solutions to improve logistics service quality (LSQ) (Wang et al., 2020a).

Organizational innovation has been recognized as a significant driver to cope with volatile business environments, because logistics service providers' (LSPs') organizational innovation enables them to develop new and unique services as a basis for non-imitable and long-term competitive advantage (Chapman et al., 2003; Grawe, 2009). The empirical study by Wang et al. (2020b) on logistics innovation capability, based on the resource-based view (RBV), demonstrated the applicability of these capabilities for mitigating supply chain risks. This study addresses the RBV's shortcoming on logistics innovation capability, which assumes a static set of resources. The environment during the pandemics is not static, but dynamic, with frequent changes and disruptions. Furthermore, this study combines the DCF with the RV to answer the call for more middle-range theorizing in LM (Stank et al., 2017, p. 15; Craighead et al., 2016, p. 246; Pellathy et al., 2018). Applying middle-range theorizing, this study seeks to explain phenomena unique to supply chain management (SCM) and logistics management (LM) by focusing on the specific mechanisms of creating innovation-oriented capabilities that strengthen resilience, improve LSQ and firm performance within the particular context of the COVID-19 pandemic.

Although there are several empirical studies on the mechanism of creating innovationoriented capabilities with the help of customers (Chapman et al., 2003; Wagner and Sutter, 2012; da Mota Pedrosa et al., 2015), buyer-supplier relations (Ivan Su et al., 2011) or the synergetic effect of innovation interactions between firms (Wang et al., 2020c), there is very limited research on the role of inter-firm resources for LSPs' innovation-oriented capabilities or how these capabilities can be applied to absorb the impacts of the COVID-19 pandemic and to recover to a better state (dynamic recovery). In addition, although horizontal cooperation or collaboration between competitors has enjoyed great significance and wide application in LSPs for years (Wallenburg and Schäffler, 2016; Brandenburger and Nalebuff, 2021), the LM and SCM literature has not paid much attention to the role of inter-firm resources during the pandemic period (Kilpatrick and Barter, 2020). 
Last but not least, despite the obvious significance of risk management and mitigating risks in supply chains (Kurniawan et al., 2017; Chopra and Sodhi, 2004; Christopher et al., 2011; Heckmann et al., 2015) and despite a mature body of knowledge on supply chain disruption over the past two decades (Xu et al., 2020), innovation-oriented dynamic capabilities have only attracted little attention in connection with very specific supply chain disruptions such as those resulting from epidemic outbreaks like SARS, MERS, Ebola, and most recently, coronavirus. To fill this gap, this study investigates the role of LSPs' innovation capability on their capability to absorb disruptions (Sheffi and Rice, 2005) and to recover by considering supply chain dynamics (Adobor and McMullen, 2018) during the pandemic. Thus, this research extends the diversity of categories influencing LSPs' disruption management to include innovation management in order to promote cross-disciplinary research on supply chain disruption.

In filling the aforementioned gaps, this paper contributes to LM and SCM literature and managerial practice by developing a multi-theoretical view on sustaining logistics resilience and firm performance during the pandemic. This study also addresses the shortcoming of the RBV and applies middle-range theorizing. Furthermore, this paper investigates the role of inter-firm resources as antecedent to innovation and the role of LSPs' innovation-oriented dynamic capability to improve their resilience, LSQ and firm performance in the pandemic context. Finally, this research provides results that help managers with regard to their strategic and operational decisions related to COVID-19.

The study has the following research question: Which innovation-related resources and capabilities are supportive for firm performance and resilience during COVID-19?

The study develops a conceptual framework using a multi-theoretical perspective. The literature on dynamic capabilities, innovation, LSQ, dynamic resilience and firm performance was reviewed, subsequently linking these to a conceptual framework. To explore the issues, the paper is organized as follows. Section 1 presents the introduction. Section 2 introduces the conceptual framework and hypotheses. Section 3 describes the data collection process and the empirical testing of the model: principal component analysis is utilized to verify scale validity for the latent variables. Spearman's correlation and $p$-values are utilized to evaluate the strength and direction of the relationships between the independent and dependent variables. Section 4 presents a discussion of the key issues that arise from the paper including implications for theory, practice and study limitations.

\section{Theory and hypotheses}

A number of researchers have proposed different supply chain research streams for COVID-19 specifically or pandemics in general. Thus, individual frameworks for agile, lean, sustainable, digital or resilient supply chains are proposed by Dolgui et al. (2020) for conceptualizing reconfigurable supply chains. Craighead et al. (2020) consider the key tenets of well-known and emerging theories to help supply chain managers formulate responses to pandemics but steer clear from the RBV or transaction costs economics which represent those grand (or so-called general) theories that have been extensively applied by supply chain researchers (p. 841). This study follows the top-down strategy or "theorizing at the middle range" (Stank et al., 2017) while contextualizing existing grand theories like the DCF in combination with the RV and validating them with empirical data (Craighead et al., 2016, p. 243; Swanson et al., 2020) in a particular domain of knowledge.

Central to the conceptual framework is the DCF in combination with the RV. Although both DCF and RV are rooted in the RBV, they address the latter's shortcomings regarding a firm's resources and capabilities. Thus, this paper assumes that it is not enough for a firm to use a static set of resources which are rare, valuable and difficult to imitate in order to achieve and sustain competitive advantage, which would be in line with the RBV (Barney, 1991). 
IJLM

33,2

502

Rather, a firm uses a dynamic set of resources and capabilities, also because during pandemics the environment is not static (as the RBV assumes) but dynamic, with frequent changes and disruptions. The DCF was proposed by Teece et al. (1997) and emphasizes the importance of the capacity for continuous innovation coupled with the management capability to effectively coordinate and redeploy internal and external competences (Teece et al, 1997, p. 515). The author shares the view of Hamel and Välikangas (2003) that this capacity is essential to resilience in order to benefit from amalgamations of innovative problem-solving capabilities so as to quickly evolve without adverse effects to the organization in dynamic changing environments.

This paper focuses on two distinct components in the literature: disruption absorption (robustness) and recovery in a dynamic environment. They are decisive for a firm's dynamic resilience, which comprises a set of dynamic capabilities to leverage its innovation power and adapt to a changing market environment during the pandemic.

This set of dynamic capabilities is seen by the author as the availability of organizational structures and managerial processes to ensure disruption absorption (robustness) and recoverability as two distinct components influencing the LSQ that will support firm performance during the pandemic. Thus, this research addresses different managerial and organizational processes or "the ways things are done in the firm" or its "routines" (Teece and Pisano, 1998, p. 197) in order to

- Absorb the impact of the COVID-19-related disruptive events through resisting the change without adaptation of the initial equilibrium (Klibi et al., 2010; Sheffi and Rice, 2005) and

- Recover to a better state than competitors so as to gain a competitive advantage (Hamel and Välikangas, 2003), despite internal or external disruptions (Kitano, 2004) and supply chain dynamics (Adobor and McMullen, 2018).

The author believes that the way things are done in a firm (routines) depends on firm-specific assets (referred to as "resources" in the DCF), difficult or impossible to imitate, and external relations with suppliers or competitors (referred to as "positions" in the DCF). The set of dynamic capabilities depends on the level of current logistics knowhow and leveraging internal resources, organizational competences and complementary assets in a firm. The exploitation of external sources of information and knowhow across a firm's frontiers in order to generate, accept and implement new ideas, processes, products or services is an important antecedent for the dynamic capability to innovate (Chesbrough, 2017; Singh et al., 2021). The constructs of dynamic resilience and organizational learning are referred as "processes" in the DCF (Teece and Pisano, 1998, p. 197).

Although the study assumes opportunistic behavior in cooperative and coopetitive relations due to reduction in search and information costs, in negotiating costs, and in enforcement costs, this paper focuses on the benefits from this inter-firm relation as a source of the capability to innovate neglecting the benefits according to the transaction cost economics. Thus, this research follows the RV view and regards inter-firm collaborations as the way to strengthen individual and organizational absorptive capacities (Cohen and Levinthal, 1990, p. 134) and to exploit complementary capabilities necessary for adapting to disruptions and recovering during the pandemic in order to achieve competitive advantage. For example, LSPs can combine their expertise or resources in unique ways along the value chain (Dyer and Singh, 1998, p. 661) in order to increase the speed of adaptation to disruptions or the speed of recovery during the pandemic.

This study combines these general theories and their predictions concerning resources, relations and firm performance with the underlying pandemic situation in order to create new knowledge on the one hand and ground the conceptual framework in the LM context on the 
other hand. Such an approach enables the observing of selected factors influencing firm performance among LSPs across a range of disruptions in connection with the pandemic. This conceptual framework should provide new, testable insights into how and why some LSPs outperform others during COVID-19.

Following context-specific dependent and independent variables are suggested to develop hypotheses.

2.1 Organizational learning and inter-firm resources as antecedents to innovation In the conceptual framework, the capacity to innovate, a term first used by Burns and Stalker (1961), encompasses the leveraging of internal sources of knowledge through organizational learning. Organizational learning is traditionally viewed as part of an innovation process (Chesbrough, 2017). Gaining new knowledge from the external sources, namely research institutes, universities, consultants, suppliers, customers and competitors, is known as "inbound open innovation" in innovation management literature (Chesbrough, 2017; Singh et al., 2021). Both constructs will be explained in the following.

\subsection{Organizational learning}

Calantone et al. (2002, p. 515) propose four components that support the learning process: "commitment to learning, shared vision, open-mindedness, and intra-organizational knowledge sharing". The importance to the firm's success of the ability to assimilate, disseminate and exploit information at all levels of the firm both quickly and effectively is backed up by empirical evidence: using data from 230 firms, Wong (2013) found that internal information sharing on environmental management contributes to corporate environmental adaptability. Yang and Lirn (2017) showed that cross-functional operation, teamwork, organizational culture, knowledge and skills enabled Taiwanese container logistics operators to adapt their logistics services in response to customers' requirements and enhance logistics performance. Lee and Song (2015) discovered that useful information or knowhow existing within shipping companies facilitates organizational innovation and improves service flexibility, and service responsiveness.

This research also assumes that information sharing supports information exchange and coordination across business functions. Firms that did not invest in organizational learning prior to the pandemic may be limited in their response paths, because dynamic capabilities are built up slowly through practice and repetition (Dierickx and Cool, 1989; Teece et al., 1997).

\subsection{Inter-firm resources}

Challenges stemming from COVID-19 make the concept of collaboration and the mix of competition and cooperation (coopetition) as important today as when it was first discussed in the literature 20 years ago (Dyer and Singh, 1998; Brandenburger and Nalebuff, 1996). In the conceptual framework, two types of external knowledge sources are considered: gaining new knowledge from business partners (collaboration) and gaining new knowledge from competitors (coopetition).

Collaboration refers to two or more parties working together long-term by sharing information, resources, risks and rewards to improve joint firm performance in order to generate joint competitive value (Ralston et al., 2020). Collaboration increases responsiveness toward supply chain disruptions (Scholten and Schilder, 2015). Collaborations along the supply chain are helpful to increase efficiency (Shou et al., 2017) and transparency (Christopher and Peck, 2004), to fulfill customer needs (Ralston et al., 2020), to achieve innovation (Paula et al., 2020), and to facilitate the creation and sharing of knowledge to reduce uncertainty (Christopher and Peck, 2004). Coopetition, enabling companies to integrate external resources through networking, is popular in daily business and research (Brandenburger and Nalebuff, 2021; Bengtsson and Kock, 2014). This study considers 
IJLM

33,2

504

coopetition as a proactive strategy for successful resilience, because firms benefit from this inter-firm relation as a source of their capability to innovate.

The importance of collaboration and coopetition along the supply chain is backed up by empirical evidence: applying the RBV, Brandon-Jones et al. (2014) studies 264 UK manufacturing plants and found that information sharing along supply chains is an antecedent of visibility, which is positively related with supply chain resilience (SCRES) and robustness. Kumar et al. (2018) utilized empirical data on 171 multi-industry Indian respondents to find that the misalignment of joint planning and of resource sharing appears to not directly influence firm performance, but indirectly through dynamic capabilities. This research corroborates Blome et al. (2014) who found evidence from 259 European manufacturing firms that incorrectly aligned demand and supply side collaboration indirectly impacts performance.

Having acknowledged the above, this paper views the leveraging of internal sources of knowledge (organizational learning) and the leveraging of external sources of knowledge arising from the collaborative or coopetitive inter-firm relations as independent variables representing the ability to innovate. This leads to the following hypotheses:

H1. There is a relationship between organizational learning and innovation. Firms with higher levels of organizational learning will achieve significantly different capacity to innovate compared to firms without higher levels of organizational learning.

H2. There is a relationship between inter-firm resources and innovation. Firms with higher levels of inter-firm resources will achieve significantly different capacity to innovate compared to firms without higher levels of inter-firm resources.

\subsection{Dynamic resilience and innovation}

There are different perspectives on SCRES (Tukamuhabwa et al., 2015) or supply chain disruption (Xu et al., 2020; Bier et al., 2020) in the literature. The context of the COVID-19 pandemic has motivated a new rise in SCRES literature. Many researchers are shaping future research, proposing ways for the simultaneous transformation of some processes and process change with the concept of "transiliency" (Craighead et al., 2020), or new conceptual perspective on SCRES such as "SC viability", an ability of a supply chain to survive under long-term, severe and unpredictably scaling disruptions (Ivanov and Dolgui, 2020). Ivanov (2021) outlines four strategies of SC viability derived from investigating the general characteristics of adaption strategies during the COVID-19 pandemic.

Furthermore, since SCRES lacks a conceptual lens related to pandemic-caused disruptions, other scholars propose different views on disruptions in this context. To author's opinion, risk mitigation strategies in the pandemic context are likely to encompass all five categories of risks proposed by Christopher et al. (2011):

- Process risks and control risks relating to COVID-19-related disruptions internal to a firm,

- Demand risks and supply risks, relating to COVID-19-related disruptions internal to the supply chain but external to the firm and

- Environmental risks, relating to disruptions external to the supply chain and the firm.

This study views pandemic-related disruptions as more challenging than disruptions in connection with natural disasters (e.g. the tsunami in Japan in 2011) or man-made catastrophes (e.g. blocking the Suez Canal for six days in March 2021). In addition, especially global supply chains can experience longer disruption duration or its simultaneous propagation at different supply chain stages (Ivanov, 2020). Craighead et al. (2020, p. 839) also underline that pandemics differ from typical supply chain disruptions along three interrelated dimensions: the global, cross-industrial scope of the pandemics; back and forth 
waves of infections without a typical spillover with minor ripples, mitigated or exacerbated by governmental decisions; and extreme effects on both supply and demand sides. Thus, to author's opinion, SCRES differs during the current pandemic from SCRES during non-COVID-related disruptions in the past. To mitigate these COVID-related disruptions, companies need to absorb all five categories of supply chain disruption risks while experiencing their simultaneous propagation at different supply chain stages with different country- and industry-related dynamics.

To do so, this research focuses on two distinct components in the literature:

(1) Disruption absorption (robustness) as the ability to accommodate disruptions or persist in the face of disruptions without adaptation of the initial equilibrium (Klibi et al., 2010; Sheffi and Rice, 2005) and

(2) Dynamic recoverability, the ability to recover to a better state than competitors in order to gain a competitive advantage (Hamel and Välikangas, 2003) despite internal or external disruptions (Kitano, 2004) and supply chain dynamics (Adobor and McMullen, 2018) during the pandemic.

The robustness capability of a firm describes how well it is prepared for disruptions and is able to maintain the same control when a disruption occurs. A firm's dynamic recoverability is defined as its ability to respond to disruptions in the form of timely and cost-effective recovery to progress to a better post-disruption state than that prior to the disruption. Thus, robustness is connected with a firm's capacity to organize itself when facing disorganization from external factors, whereas recoverability is connected with a firm's capacity to learn and adapt in response to disruptions.

Thus, this study considers the dynamic resilience as a firm's capability to leverage its innovation power to activate the above-mentioned two components of resilience simultaneously or consecutively, given that disruption absorption would logically and practically precede disruption recovery actions. At the same time, being robust does not necessary imply that the firm can recover. Following Holling's view (1973), a system can persist in the face of disruptions and yet lack the ability to return to an initial state after being exposed to a disruption and vice versa.

A number of studies in LM have shown that the effective use of knowledge resources is critical to improve LSQ or operational efficiency. In this study, it is assumed that innovativeness has a positive effect on the fulfillment of customers' expectations and operational efficiency as it was evidenced in the work of Bellingkrodt and Wallenburg (2015), who collected data from 284 German LSPs. The analysis by Lee and Song (2015) of 181 Korean shipping companies verified that effective knowledge management of shipping companies improves, among others, service flexibility and service responsiveness as measurements of logistics value. Yang (2016) collected evidence from 83 Taiwanese public distribution center operators that logistics learning capability is positively related to, among others, flexibility as an indicator of logistics service. Brandon-Jones et al. (2014) conducted an empirical study on 264 UK manufacturers and found that information sharing along the supply chain is an antecedent of visibility which is positively related with SCRES and robustness. Shou et al. (2017) collected data from 203 3PL providers in China to confirm that strong relationships with suppliers and customers are important to achieve superior performance if the firm is able to implement new ideas. Thus, it is believed that the ability to innovate contributes to the firm's identification, selection, utilization and understanding of novel ideas or problem-solving patterns during pandemics:

H3. There is a relationship between the capacity to innovate and dynamic resilience. Firms with greater levels of capacity to innovate will achieve significantly different dynamic resilience compared to firms without greater levels of the capacity to innovate.
Dynamic resilience capabilities 
IJLM

33,2

\section{6}

The study does not assume a direct link between innovation and firm performance, but rather an indirect one involving the constructs of dynamic resilience and LSQ as a dynamic capability of a firm. This paper draws on the results of research by Kumar et al. (2018) who provided empirical evidence that misalignment of particular measures not appear to directly influence firm performance, but indirectly through dynamic capabilities. LSPs that adapt quickly to the COVID-19-related disruptions along the value chain can offer services with enhanced custom experience in terms of LSQ in spite of the pandemic. Thus, it is assumed that higher levels of dynamic resilience can be associated with higher levels of LSQ:

H4. There is a relationship between dynamic resilience and LSQ. Firms with higher levels of dynamic resilience will achieve significantly different LSQ compared to firms without higher levels of dynamic resilience.

Following either an internal approach, in which LSPs construct attributes for assessing their services, or a more objective approach, in which customers' perceptions are compared with their expectations (Thai, 2013), many scientific studies have been conducted in order to develop LSQ scales (Bienstock et al., 1997, 2008; Rahman, 2006; Politis et al., 2014), to describe the relationship between LSQ and customer satisfaction (Mentzer et al., 2001, Kilibarda et al., 2016; Sohn et al., 2017), or to address a particular context and perspective concerning LSQ (Thongkruer and Wanarat, 2021; De and Singh, 2021). In the conceptual framework, five items are used to define LSQ. Apart from undamaged goods upon delivery and error-free transactions, the attributes of timeliness, total support of customer needs and consistency of order cycle are focused in this study. The latter three were ranked by 59 logistics/operations managers in the survey of Rahman (2006) as the three most important components that describe quality in logistics.

Finally, the conceptual framework encompasses the dimension of firm performance, also referred to as organizational performance in the literature (Richard et al., 2009). According to RBV and DCF reasoning, the differences in business performance are a consequence of a firm's internal characteristics and dynamic capabilities. Firm performance, as a key construct in management research, relates to three precise areas of organizational outcomes: financial performance, market performance and return to shareholders (Richard et al., 2009). Based on this and previous work by Shou et al. (2017) and Tseng and Liao (2015), the so-called soft measures that employees at any level of a firm can evaluate or estimate were used. Furthermore, these measures do not require the disclosure of confidential financial information such as revenue or return on investment. It is thus hypothesized:

H5. There is a relationship between LSQ and firm performance. Firms with higher levels of LSQ will achieve significantly different firm performance compared to firms without higher levels of LSQ.

Thus, the DCF and the RV, rooted in the RBV, are utilized to explain the relationships between the constructs in the conceptual framework developed by this research, which is displayed in Figure 1. Organizational learning and inter-firm resources are independent variables. Leveraging of internal sources of knowledge through organizational learning and

Figure 1.

Conceptual framework

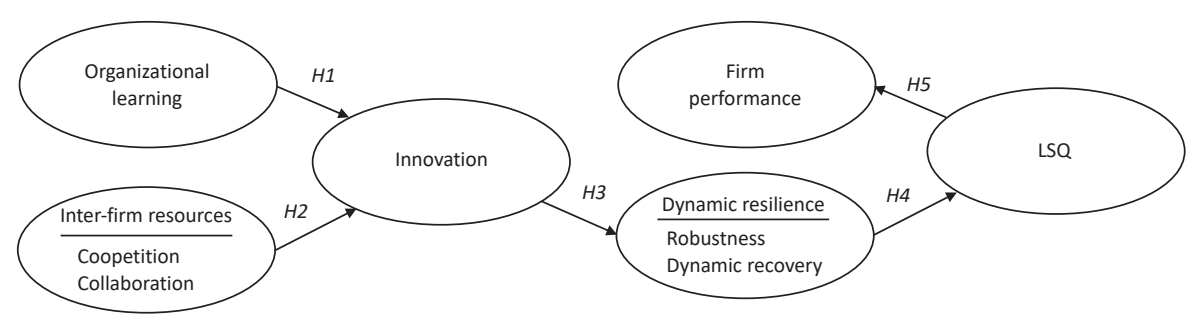


exploitation of external sources of information and knowhow across a firm's frontiers are considered as sources of innovation. In the conceptual framework, the same instruments are used in different constellations as a predictor or as an outcome variable. Thus, innovation is a dependent variable in $\mathrm{H} 1$ and $\mathrm{H} 2$, and an independent one in $\mathrm{H} 3$ where it affects the dependent variable of dynamic resilience. Dynamic resilience is a latent construct comprising robustness and dynamic recovery. As an independent variable, this study assumes that it affects the dependent variable of LSQ in H4. LSQ is an independent variable in H5 and is believed to be statistically significant for firm performance.
Dynamic resilience capabilities

\section{Methodology}

In order to statistically test the hypotheses, this paper adopts a quantitative research methodology. All constructs were operationalized following the comprehensive literature that has empirically measured and tested the relevant instruments. The construct operationalization to measure variables is presented in Appendix.

\subsection{Sample characteristics}

An online survey was launched in October 2020 via the Qualtrics online platform, using different social media channels to recruit respondents. Qualtrics's marketplace was used as a survey tool without accessing any "specialized panels" of targeted respondents which would have entailed a fee. Thus, respondents were not incentivized by monetary rewards for completing a survey (Schoenherr et al., 2015). The survey generated 145 initially valid responses over a period of one month. The response rate was approximately $7 \%$ (2,100 views/ 298 attempts to complete). The completion rate was $48.7 \%$. A closer review of the reverse coded item COOP4 revealed several respondents that were removed from the dataset for giving nonsensical answers to COOP3 and COOP4: a firm that strongly values coopetition with rivals would not be likely to also strongly avoid coopetition with rivals. After removing these respondents, 113 valid responses remained for the data analysis.

Two of the four most commonly applied techniques to assess nonresponse bias (Wagner and Kemmerling, 2010, p. 360) were followed: extrapolation and sampling nonrespondents. First, a $t$-test was performed to determine whether there is a significant difference between the two waves of respondents. The first wave of respondents, who responded before the end of the survey and did not receive a reminder, was compared with those responding after the reminder. The result from this test indicated that there was no significant difference between the two waves at the $95 \%$ confidence level. The respondents were contacted and reminded via different social media channels and bilaterally via email. Second, the comparison of 12 aftercutoff date with pre-cutoff date responses revealed strong similarities. The after-cutoff date respondents completed the full version of the online survey via the Qualtrics online platform, because it was not deactivated after the end of the survey. This small sample of after-cutoff respondents was regarded as a randomly selected sample of non-respondents. The answers of these non-respondents did not differ significantly from those of the pre-cutoff date respondents. Thus, the study is unlikely to have been impacted by nonresponse bias.

The questionnaire was designed to include employees at all levels of a firm, including front-line workers (general employees). The reason was that during the pandemic front-line workers and logistics professionals (executive and management) have been responsible for maintaining critical supply chains (Accenture, 2020) and because knowledge that is vital to the successful management of firm assets during the pandemic, may be spread across and within subunits far "removed from the original point of entry" (Cohen and Levinthal, 1990, p. 131). Respondents for this study were either employees of an LSP $(73.5 \%)$ or worked in the logistics departments of manufacturers, distributors, retailers and other types of firms that 
IJLM 33,2

\section{8}

rely on logistics services (26.5\%). The profile of respondents' companies and their characteristics is displayed in Table 1.

Table 1 shows that the vast majority of respondents are from firms located in America (45.1\%) and Europe $(29.2 \%)$. The analysis of responses revealed that $42.5 \%$ of respondents' companies employed more than 501 people, and 31.8\% employed between 51 and 500 people, and $25.7 \%$ employed less than 51 people. According to the respondents, the four most frequently performed primary services were general forwarding $(27 \%)$, distribution $(18 \%)$, container services $(10 \%)$ and warehousing $(9 \%) .16 \%$ of respondents selected other primary services. Retail or wholesale (16\%), food and beverage (12\%), and distribution (12\%) were the most frequently named primary industries. Furthermore, $28 \%$ of respondents selected others as their primary industry like maritime or humanitarian logistics.

The highly dynamic and vulnerable environment that the respondents faced during the pandemic may be characterized through an array of challenges and disruptions, as listed in the first column of Table 2. Each respondent selected at least one COVID-19-related challenge from the list with ten (multiple answers were possible): shipment delays, e.g. blank sailings of

\begin{tabular}{|c|c|c|c|c|}
\hline Category & Responses & Frequency & $\%$ & Cumulative $\%$ \\
\hline \multicolumn{5}{|l|}{ Firm type } \\
\hline & LSP & 83 & 73.5 & 73.5 \\
\hline & Logistics department & 30 & 26.5 & 100.0 \\
\hline \multicolumn{5}{|c|}{ Headquarter } \\
\hline & North America & 46 & 40.7 & 40.7 \\
\hline & South America & 5 & 4.4 & 45.1 \\
\hline & Europe & 33 & 29.2 & 74.3 \\
\hline & Asia & 20 & 17.7 & 92 \\
\hline & Africa & 4 & 3.5 & 95.6 \\
\hline & Middle East & 4 & 3.5 & 99.1 \\
\hline & Australia & 1 & 0.9 & 100.0 \\
\hline \multicolumn{5}{|l|}{ Firm size } \\
\hline & $\leq 50$ & 29 & 25.7 & 25.7 \\
\hline & $\overline{5} 1-100$ & 11 & 9.7 & 35.4 \\
\hline & $101-500$ & 25 & 22.1 & 57.5 \\
\hline & $501-1,000$ & 13 & 11.5 & 69 \\
\hline & $\geq 1,000$ & 35 & 31 & 100.0 \\
\hline Position & Executive & 31 & 27.4 & 27.4 \\
\hline & Management & 52 & 46 & 73.5 \\
\hline & General employee & 30 & 26.5 & 100.0 \\
\hline
\end{tabular}

Table 1.

Respondents' profile

\begin{tabular}{lrrlrr}
\hline Challenge & Hits & $\%$ & Adaptation & Hits & $\%$ \\
\hline Shipment delays & 64 & 57 & Remote work & 79 & 70 \\
Travel restrictions & 59 & 52 & New operational procedures & 64 & 57 \\
Supply disruptions & 58 & 51 & COVID-19 response teams & 59 & 52 \\
Financial stress & 50 & 44 & Internal COVID-19 guidelines & 58 & 51 \\
Demand disruptions & 47 & 42 & External COVID-19 guidelines & 43 & 38 \\
Mandatory shutdowns & 38 & 34 & Diversification of customer or industry & 31 & 27 \\
Health and safety & 37 & 33 & New business models & 23 & 20 \\
Lack of business continuity plan & 30 & 27 & Diversification of distribution channels & 22 & 19 \\
Loss or waste of goods & 9 & 8 & Automation & 16 & 14 \\
Other challenges & 4 & 4 & Other measures & 4 & 4 \\
& & & & &
\end{tabular}

Table 2.

COVID-19-related

challenges and adoptions of respondents 
liner services (57\%), travel restrictions (52\%) and supply disruptions $(51 \%)$ were named by more than half the 113 respondents. $45 \%$ of respondents selected at least three challenges from the list, $8 \%$ selected seven challenges or more.

To absorb these disruptions, the respondents adopted different managerial and organizational measures as it is shown in the right-hand side of Table 2. Respondents were asked to select adaptions from a list of ten (multiple answers were possible). Remote working $(70 \%)$ was the most common adaptation implemented during the pandemic. New operational procedures $(57 \%)$ and COVID-19 response teams $(52 \%)$ were the next most common adaptations. Finally, $51 \%$ of firms reported implementing internal COVID-19 guidelines, whereas $38 \%$ reported implementing external guidelines. This can be seen as an indication of how quickly firms assimilate and exploit internal vs external knowledge. Only $9 \%$ of firms developed more than six adaptations.

\subsection{Measurement scales}

A principal component analysis was made as the first step to reduce the data and extract maximum variance from the data set of 38 observed variables (without variable COOP4), which yielded eight components (Tabachnick and Fidell, 2007). After principal axis factoring the rotated eigenvalues and scree plot were looked to get confirmed the eight factors are significant factors. A rotation method was applied to obtain an optimal simple structure (Rummel, 1970) of variables in the conceptual model that should load highly, for example, on innovation for example, but should have close to zero loadings on other factors like, for example, dynamic recovery. The rotation method was used to identify most important capabilities supporting a range of constructs in the conceptual framework.

Using Statistical Product and Service Solutions (SPSS), the orthogonal rotation method of Varimax was chosen partly violating some of the previous assumptions that particular latent constructs are correlated in order to obtain a simple structure of constructs (Costello and Osborne, 2005), minimizing the number of observed variables with high loadings on each factor and making small loadings even smaller. Bartlett's test of sphericity was significant at the level of $p<0.001$ and thus confirmed that the sample has patterned relationships among variables allowing a data reduction technique. The Kaiser-Meyer-Olkin measure of 0.872 confirmed the factorability $(>0.50)$. The factor loadings in the rotated factor matrix showed that the eight factors are fairly desirable with the pre-defined observed variables per factor above the significant loading of 0.45 as suggested by Tabachnick and Fidell (2007), irrespective of sample size, for interpretive purposes. So, there was no need to rerun the analysis without some observed items. Only two observed variables, PERF4 (market share growth) and PERF5 (profitability) had cross-loadings above 0.4 ( 0.491 and 0.637 respectively) with the factor recovery. It was assumed that it is the nature of these complex observed items of market share growth and profitability, and neglected these cross-loadings in the following steps. The average communality of all items in the factor model was practically significant (0.614-0.903).

All observed variables were measured on a five-point Likert scale $(1=$ strongly agree, $5=$ strongly disagree) and computed as ordinal variables. The reliability of the model measurement was evaluated through Cronbach's alpha, followed by an assessment of the factors' composite reliability (CR) and average variance extracted (AVE). Scale reliability is established with a minimum Cronbach's alpha score of 0.7 (Nunnally, 1978, p. 245): the Cronbach's alpha values range between 0.83 and 0.93 (see Appendix). CR addresses the internal reliability of all the observed variables in their measurement of each latent construct. AVE measures the amount of variance in the measured variables captured by the latent variable. Fornell and Larcker (1981, p. 45) recommend a CR value of 0.6 or more and an AVE greater than 0.5. All constructs were based on reliable observed items (CR values were in the range of 0.75-0.93 as shown in Appendix), demonstrating that the observed variables have

\section{Dynamic resilience capabilities}


IJLM

33,2

510

adequate internal consistency and are sufficient to represent the construct. As it is listed in Appendix, the AVE of four constructs was greater than 0.5 and slightly below $0.5(0.47-0.5)$ for the other latent constructs, apart from the construct firm performance (0.39). These values below 0.5 were accepted, because if AVE is less than 0.5 , but composite reliability is greater than 0.6, the convergent validity of the construct is still adequate (Fornell and Larcker, 1981, p. 46).

Discriminant validity provides evidence that a latent construct is distinct from other constructs and captures the phenomena and concepts that other constructs do not. If the AVE is greater than the correlation square of this independent variable with the dependent construct following the component correlation matrix, discriminant validity is established. All AVE values are greater than the respective correlation squares in the component correlation matrix. Thus, the evidence for both convergent and discriminant validity establishes the construct validity.

\subsection{Results of hypothesis testing}

Due to non-normally distributed variables on ordinal scales, an analysis applying non-parametric Spearman's correlation tests was performed to check the agreement on the ranking of the answers between latent variables from the hypotheses. Composite variables for each latent variable were computed following the loadings of observed variables on each component from the Varimax rotated matrix.

As displayed in Table 3, all five hypotheses, H1, H2, H3, H4 and H5, find support in terms of statistically significant positive correlations. H3 predicts that higher values for innovation in LSPs may be positively associated with higher values for dynamic resilience. Table 3 shows that the Spearman's correlation coefficient is positive and statistically significant, i.e. $p<0.01$. Table 3 also reveals a significant positive correlation between innovation with organizational learning $(\mathrm{H} 1)$ and inter-firm resources (H2), respectively, at the 0.01 level of significance. With regard to $\mathrm{H} 4$, which predicts that a higher level of dynamic resilience may be positively associated with the higher level of LSQ, a statistically significant and strong positive correlation coefficient, i.e. $p<0.01$, were obtained.

Finally, as displayed in Table 3, H5 finds support in terms of significantly positive coefficients $(p<0.01)$ : higher level of LSQ is associated with a higher level of firm performance in LSPs. Thus, all hypotheses were supported.

\section{Conclusion and discussion}

In this study, a range of innovation-oriented capabilities for achieving more dynamic resilience were bundled in a model and were found to be statistically significant for LSQ and firm performance. Factor analysis was conducted to arrange the identified capabilities into six latent factors: organizational learning capability, inter-firm resources, innovation, dynamic resilience, LSQ and firm performance. Correlation analysis was employed to test the

Table 3.

Descriptive statistics and Spearman's correlation coefficient

\begin{tabular}{lcccccccr}
\hline Variables & Mean & SD & 1 & 2 & 3 & 4 & 5 & 6 \\
\hline Dynamic resilience (1) & 13.714 & 5.102 & 1.000 & & & & & \\
Inter-firm resources (2) & 7.377 & 2.434 & $0.299^{*}$ & 1.000 & & & & \\
Innovation (3) & 6.887 & 3.222 & $0.476^{*}$ & $0.542^{*}$ & 1.000 & & & \\
Logistics service quality (4) & 6.8094 & 2.775 & $0.615^{*}$ & $0.244^{*}$ & $0.484^{*}$ & 1.000 & & \\
Performance (5) & 6.2033 & 2.546 & $0.658^{*}$ & $0.352^{*}$ & $0.536^{*}$ & $0.670^{*}$ & 1.000 & \\
Organizational learning (6) & 7.742 & 3.379 & $0.427^{*}$ & $0.507^{*}$ & $0.637^{*}$ & $0.391^{*}$ & $0.476^{*}$ & 1.000 \\
Note(s): ${ }^{*} p<0.01 ; n=113$ & & & & & & & & \\
\hline
\end{tabular}


research hypotheses. The findings indicate that higher values on the factors organizational learning capability (H1), inter-firm resources (H2) and innovation (H3), are associated with a higher level of dynamic resilience during COVID-19. The higher level of dynamic resilience itself is positively associated with higher LSQ (H4) and better firm performance (H5). This research indicates that dynamic resilience is important since COVID-19-related disruptions are more challenging than those connected with natural disasters or man-made catastrophes. Their duration is longer and they propagate at different supply chain stages with different country- and industry-related dynamics which can occur simultaneously. In order to absorb them or recover, LSPs have to leverage their innovation power to activate two components of resilience simultaneously or consecutively.

\subsection{Implications for researchers}

From a research point of view, the results support middle-range thinking, coined by Mills (1959) and Merton (1967a, b). Grand theories were applied to conduct "a theory-oriented empirical inquiry" (Soltani et al., 2014, p. 1013). The identification of the statistical significance of selected capabilities, on the one hand, infers that an LSP or a firm with an internal logistics department should use a bundle of internal and external resources during a pandemic to achieve superior dynamic resilience. On the other hand, this study supports the view that these distinctive capabilities are valuable for enhancing LSQ and firm performance during a pandemic. In addition, the findings provide empirical support to the capabilitybuilding view, which asserts the importance of internal resource investment and external relationship maintenance with partners and rivals (Yang and Lirn, 2017; Teece et al., 1997). Finally, the application of distinctive capabilities is helpful to enhance LSQ and firm performance during COVID-19. Framing the role of innovation in this manner contributes to the logistics strategy literature and SCRES literature.

\subsection{Managerial implications}

This study shows that a range of internal and external resources are not only decisive for a greater level of innovation, but also improve the dynamic resilience to outperform others during COVID-19 in terms of LSQ and firm performance. From a managerial perspective, the following implications can be addressed based on the empirical results. The development of internal and external resources enables the enhancement of dynamic resilience, which is crucial during crises like COVID-19. The learning capability of a company is decisive for developing necessary adaptations during COVID-19. According to the analyzed loading factors, it can be influenced by measures like improvements to how a firm distributes new knowledge (0.758), effective training (0.833) and cross-functional collaboration (0.707). Logistics operators should know that investing in inter-firm relationships with business partners on a long-term basis (0.723), collaborating (0.908), learning from rivals $(0.906)$ and looking for a win-win relationship (0.894) with rivals are statistically significant for the innovativeness, which in turn, is important for dynamic resilience during COVID-19. These findings are useful for executives and logistics managers to improve these capabilities to gain a competitive advantage during pandemics and to identify their strengths and weaknesses in their ability to develop critical capabilities for highly turbulent and dynamic situations in their operating environment, and therefore provide a path for improvement.

\subsection{Limitations and future research}

First, the results of this study do not imply that the critical capabilities identified are the only ones that are statistically significant for increasing dynamic resilience during the pandemic. Second, in October 2020, the COVID-19 pandemic was at different stages in different countries, so that the level to which firms were affected was different, and although data were

\section{Dynamic resilience capabilities}


IJLM 33,2

\section{2}

collected during one month only, due to the high dynamics of the pandemic, data can refer to different stages of disruptions, experienced by respondents even in the same country. Third, by limiting the time frame for data collection to one month, the sample $(n=113)$ was too small to conduct confirmatory factor analysis or structural equation modeling. This study is set in the context of COVID-19, and it could not be proved whether the conceptual framework is generalizable to other crises or particular industries, but it would be worthwhile to examine this in the future.

Other limitations relate to the measures of service quality used in the study. For example, the construct of LSQ does not encompass the attribute of corporate image, which was ranked as third after customer focus quality and order fulfillment quality by 86 LSPs and 85 customers in Singapore (Thai, 2013). Furthermore, due to the focus of the study on the innovation-oriented capabilities of LSPs, it might be also very helpful to include the attribute "logistics information technology" (Bienstock et al., 2008) in future research to assess the LSPs' capabilities to apply technologies, to introduce technological innovations, and to maintain high levels of transparency during disruptive events (although information quality was ranked as the least agreed-upon factor of logistics quality in the study by Thai (2013)).

Another limitation is that no mediating effect of LSQ on the relationship between innovation-oriented capabilities and firm performance was tested. By exploiting the full potential of innovation-oriented capabilities, an LSP can achieve higher levels of LSQ and improve its performance. For example, the study by Fernandes et al. (2018) in the Brazilian lubricant oil market has shown that LSQ is a mediator between logistics capabilities and customer satisfaction. Therefore, future research is encouraged to test whether LSQ mediates the relationship between innovative capabilities and firm performance during a pandemic.

\section{References}

Accenture (2020), “COVID-19: freight and logistics response”, available at: https://www.accenture.com/ cn-en/insights/industrial/coronavirus-freight-logistics-recovery (accessed 24 October 2020).

Adobor, H. and McMullen, R.S. (2018), "Supply chain resilience: a dynamic and multidimensional approach", The International Journal of Logistics Management, Vol. 29 No. 4, pp. 1451-1471, doi: 10.1108/IJLM-04-2017-0093.

Barney, J. (1991), "Firm resources and sustained competitive advantage", Journal of Management, Vol. 17 No. 1, pp. 99-120, doi: 10.1177/F014920639101700108.

Bellingkrodt, S. and Wallenburg, C.M. (2015), "The role of customer relations for innovativeness and customer satisfaction: a comparison of service industries", The International Journal of Logistics Management, Vol. 26 No. 2, pp. 254-274, doi: 10.1108/IJLM-06-2012-0038.

Bengtsson, M. and Kock, S. (2014), "Coopetition - quo vadis? Past accomplishments and future challenges", Industrial Marketing Management, Vol. 43 No. 2, pp. 180-188, doi: 10.1016/j. indmarman.2014.02.015.

Betti, F. and Ni, J. (2020), "How China can rebuild global supply chain resilience after COVID-19", available at: https://www.weforum.org/agenda/2020/03/coronavirus-and-global-supply-chains (accessed 24 October 2020).

Bienstock, C.C., Mentzer, J.T. and Bird, M.M. (1997), "Measuring physical distribution service quality", Journal of the Academy of Marketing Science, Vol. 25 No. 1, pp. 31-44, doi: 10.1007/BF02894507.

Bienstock, C.C., Royne, M.B., Sherrell, D. and Stafford, T.F. (2008), "An expanded model of logistics service quality: incorporating logistics information technology", International Journal of Production Economics, Vol. 113 No. 1, pp. 205-222, doi: 10.1016/j.jpe.2007.03.023.

Bier, T., Lange, A. and Glock, C.H. (2020), "Methods for mitigating disruptions in complex supply chain structures: a systematic literature review", International Journal of Production Research, Vol. 58 No. 6, pp. 1835-1856, doi: 10.1080/00207543.2019.1687954. 
Blome, C., Paulraj, A. and Schuetz, K. (2014), "Supply chain collaboration and sustainability: a profile deviation analysis", International Journal of Operations and Production Management, Vol. 34 No. 5, pp. 639-663, doi: 10.1108/IJOPM-11-2012-0515.

Brandenburger, A.M. and Nalebuf, B.J. (1996), Co-opetition, Doubleday, New York, NY.

Dynamic resilience capabilities

Brandenburger, A.M. and Nalebuff, B. (2021), "The rules of co-opetition", Harvard Business Review, Vol. 99 No. 1, pp. 48-57.

Brandon-Jones, E., Squire, B., Autry, C.W. and Petersen, K.J. (2014), “A contingent resource-based perspective of supply chain resilience and robustness", Journal of Supply Chain Management, Vol. 50 No. 3, pp. 55-73, doi: 10.1111/jscm.12050.

Burns, T. and Stalker, G.M. (1961), The Management of Innovation, Tavistock Publishing, London.

Calantone, R.J., Cavusgil, S.T. and Zhao, Y. (2002), "Learning orientation, firm innovation capability, and firm performance", Industrial Marketing Management, Vol. 31 No. 6, pp. 515-524, doi: 10.1016/S0019-8501(01)00203-6.

Chapman, R.L., Soosay, C. and Kandampully, J. (2003), "Innovation in logistic services and the new business model: a conceptual framework", International Journal of Physical Distribution and Logistics Management, Vol. 33 No. 7, pp. 630-650, doi: 10.1108/09600030310499295.

Chesbrough, H. (2017), “The future of open innovation”, Research-Technology Management, Vol. 60 No. 6, pp. 29-35, doi: 10.1080/08956308.2017.1373048.

Choi, T.Y., Rogers, D. and Vakil, B. (2020), "Coronavirus is a wake- up call for supply chain management”, available at: https://hbr.org/2020/03/coronavirus-is-a-wake-up-call-for-supplychain-management (accessed 23 May 2021).

Chopra, S. and Sodhi, M.S. (2004), "Managing risk to avoid supply-chain breakdown", MIT Sloan Management Review, Vol. 46 No. 1, pp. 53-62.

Christopher, M. and Peck, H. (2004), "Building the resilient supply chain”, The International Journal of Logistics Management, Vol. 15 No. 2, pp. 1-14, doi: 10.1108/09574090410700275.

Christopher, M., Mena, C., Khan, O. and Yurt, O. (2011), "Approaches to managing global sourcing risk”, Supply Chain Management: An International Journal, Vol. 16 No. 2, pp. 67-81, doi: 10.1108/ 13598541111115338.

Cohen, W.M. and Levinthal, D.A. (1990), "Absorptive capacity: a new perspective on learning and innovation", Administrative Science Quarterly, Vol. 35 No. 1, pp. 128-152, doi: 10.2307/ 2393553.

Costello, A.B. and Osborne, J.W. (2005), "Best practices in exploratory factor analysis: four recommendations for getting the most from your analysis", Practical Assessment, Research and Evaluation, Vol. 10 No. 7, pp. 1-9, doi: 10.7275/JYJ1-4868.

Craighead, C.W., Ketchen, D.J. and Cheng, L. (2016), "Goldilocks" theorizing in supply chain research: balancing scientific and practical utility via middle-range theory", Transportation Journal, Vol. 55 No. 3, pp. 241-257.

Craighead, C.W., Ketchen, D.J. and Darby, J.L. (2020), "Pandemics and supply chain management research: toward a theoretical toolbox", Decision Sciences, Vol. 51 No. 4, pp. 838-866, doi: 10. 1111/deci.12468.

da Mota Pedrosa, A., Blazevic, V. and Jasmand, C. (2015), "Logistics innovation development: a microlevel perspective", International Journal of Physical Distribution and Logistics Management, Vol. 45 No. 4, pp. 313-332, doi: 10.1108/IJPDLM-12-2014-0289.

De, A. and Singh, S.P. (2021), "A resilient pricing and service quality level decision for fresh agriproduct supply chain in post-COVID-19 era", The International Journal of Logistics Management, Vol. ahead-of-print No. ahead-of-print. doi: 10.1108/IJLM-02-2021-0117.

Dierickx, I. and Cool, K. (1989), "Asset stock accumulation and the sustainability of competitive advantage: reply", Management Science, Vol. 35 No. 12, pp. 1504-1511. 
IJLM

33,2

514

Dolgui, A., Ivanov, D. and Sokolov, B. (2020), "Reconfigurable supply chain: the X-network", International Journal of Production Research, Vol. 58 No. 13, pp. 4138-4163, doi: 10.1080/00207543.2020.1774679.

Doz, Y. and Shuen, A. (1988), "From intent to outcome: a process framework for partnerships", Research and the Development of Pedagogical Materials, Vol. 88 No. 46, pp. 1-26.

Dyer, J.H. and Singh, H. (1998), "The relational view: cooperative strategy and sources of interorganizational competitive advantage", Academy of Management Review, Vol. 23 No. 4, pp. 660-679, doi: 10.5465/AMR.1998.1255632.

Essuman, D., Boso, N. and Annan, J. (2020), "Operational resilience, disruption, and efficiency: conceptual and empirical analyses", International Journal of Production Economics, Vol. 229 No. 2020, pp. 1-11, doi: 10.1016/j.jpe.2020.107762.

Fawcett, S.E., Wallin, C., Allred, C., Fawcett, A.M. and Magnan, G.M. (2011), "Information technology as an enabler of supply chain collaboration: a dynamic capabilities perspective", Journal of Supply Chain Management, Vol. 47 No. 1, pp. 28-59, doi: 10.1111/j.1745-493X.2010.03213.x.

Fernandes, D.W., Moori, R.G. and Filho, V.A.V. (2018), "Logistic service quality as a mediator between logistics capabilities and customer satisfaction", Revista de Gestão, Vol. 25 No. 4, pp. 358-372, doi: 10.1108/REGE-01-2018-0015.

Fornell, C. and Larcker, D.F. (1981), "Evaluating structural equation models with unobservable variables and measurement Error", Journal of Marketing Research, Vol. 18 No. 1, pp. 39-50, doi: $10.2307 / 3151312$.

Grawe, S.J. (2009), "Logistics innovation: a literature-based conceptual framework", The International Journal of Logistics Management, No. 20, pp. 360-377, doi: 10.1108/09574090911002823.

Hamel, G. and Välikangas, L. (2003), "The quest for resilience", Harvard Business Review, Vol. 81 No. 9, pp. 52-63.

Heckmann, I., Comes, T. and Nickel, S. (2015), "A critical review on supply chain risk - definition, measure and modelling”, Omega, Vol. 52, April, pp. 119-132, doi: 10.1016/j.omega.2014.10.004.

Holling, C.S. (1973), "Resilience and stability of ecological systems", Annual Review of Ecology and Systematics, Vol. 4 No. 1, pp. 1-23, doi: 10.1146/annurev.es.04.110173.000245.

International Monetary Fund (2020), "The great lockdown: worst economic downturn since the great depression”, available at: https://blogs.imf.org/2020/04/14/the-great-lockdown-worst-economicdownturn-since-the-great-depression/ (accessed 17 April 2021).

Ivan Su, S., Gammelgaard, B. and Yang, S.L. (2011), "Logistics innovation process revisited: insights from a hospital case study", International Journal of Physical Distribution and Logistics Management, Vol. 41 No. 6, pp. 577-600, doi: 10.1108/09600031111147826.

Ivanov, D. (2020), "Predicting the impacts of epidemic outbreaks on global supply chains: a simulation-based analysis on the coronavirus outbreak (COVID-19/SARS-CoV-2) case", Transportation Research Part E: Logistics and Transportation Review, Vol. 136, April, pp. 1-14, doi: 10.1016/j.tre.2020.101922.

Ivanov, D. (2021), "Supply Chain Viability and the COVID-19 pandemic: a conceptual and formal generalisation of four major adaptation strategies", International Journal of Production Research, Vol. 59 No. 12, pp. 1-18, doi: 10.1080/00207543.2021.1890852.

Ivanov, D. and Dolgui, A. (2020), "Viability of intertwined supply networks: extending the supply chain resilience angles towards survivability. A position paper motivated by COVID-19 outbreak", International Journal of Production Research, Vol. 58 No. 10, pp. 2904-2915, doi: 10.1080/00207543.2020.1750727.

Kilibarda, M., Nikolicic, S. and Andrejic, M. (2016), "Measurement of logistics service quality in freight forwarding companies a case study of the Serbian market", The International Journal of Logistics Management, Vol. 27 No. 3, pp. 770-794, doi: 10.1108/IJLM-04-2014-0063.

Kilpatrick, J. and Barter, L. (2020), “COVID-19: managing supply chain risk and disruption”, available at: https://www2.deloitte.com/content/dam/Deloitte/ca/Documents/finance/Supply-Chain_POV_ EN_FINAL-AODA.pdf (accessed 24 October 2020). 
Kitano, H. (2004), "Biological robustness”, Nature Reviews Genetics, Vol. 5 No. 11, pp. 826-837, doi: $10.1038 / \mathrm{nrg} 1471$.

Klibi, W., Martel, A. and Guitouni, A. (2010), "The design of robust value-creating supply chain networks: a critical review", European Journal of Operational Research, Vol. 203 No. 2, pp. 283-293, doi: 10.1016/j.ejor.2009.06.011.

Kumar, G., Subramanian, N. and Maria Arputham, R. (2018), "Missing link between sustainability collaborative strategy and supply chain performance: role of dynamic capability", International Journal of Production Economics, Vol. 203, pp. 96-109, doi: 10.1016/j.jpe.2018.05.031.

Kurniawan, R., Zailani, S.H., Iranmanesh, M. and Rajagopal, P. (2017), "The effects of vulnerability mitigation strategies on supply chain effectiveness: risk culture as moderator", Supply Chain Management, Vol. 22 No. 1, pp. 1-15, doi: 10.1108/SCM-12-2015-0482.

Lee, E.-S. and Song, D.-W. (2015), "The effect of shipping knowledge and absorptive capacity on organizational innovation and logistics value", International Journal of Logistics Management, Vol. 26 No. 2, pp. 218-237, doi: 10.1108/IJLM-01-2013-0011.

Lin, J. and Lanng, C. (2020), "Here's how global supply chains will change after COVID-19", available at: https://www.weforum.org/agenda/2020/05/this-is-what-global-supply-chains-will-look-likeafter-COVID-19/ (accessed 24 October 2020).

Mentzer, J.T., Flint, D.J. and Hult, G.T.M. (2001), "Logistics service quality as a segment-customized process”, Journal of Marketing, Vol. 65 No. 4, pp. 82-104, doi: 10.1509/Fjmkg.65.4.82.18390.

Merton, R.K. (1967a), On Theoretical Sociology. Five Essays, Old and New, Free Press, New York, NY.

Merton, R.K. (1967b), On Theoretical Sociology, Including Part 1 of Social Theory and Social Structure, Free Press, New York, NY.

Mills, C.W. (1959), The Sociological Imagination, Oxford University Press, New York, NY.

Mody, A. (1993), "Learning through alliances", Journal of Economic Behavior and Organization, Vol. 20 No. 2, pp. 151-170, doi: 10.1016/0167-2681(93)90088-7.

Nunnally, J.C. (1978), Psychometric Theory, McGraw-Hill, New York, NY.

Paula, I.C.d., Campos, E.A.R.D., Pagani, R.N., Guarnieri, P. and Kaviani, M.A. (2020), "Are collaboration and trust sources for innovation in the reverse logistics? Insights from a systematic literature review", Supply Chain Management, Vol. 25 No. 2, pp. 176-222, doi: 10. 1108/SCM-03-2018-0129.

Pellathy, D.A., Mollenkopf, D.A. and Stank, T.P. (2018), "Middle-range theorizing on logistics customer service", International Journal of Physical Distribution and Logistics Management, Vol. 48 No. 1, pp. 2-18, doi: 10.1108/IJPDLM-10-2017-0329.

Politis, Y., Giovanis, A. and Binioris, S. (2014), "Logistics service quality and its effects on customer satisfaction in the manufacturing companies' supply chains: empirical evidence from Greece", Journal of Modelling in Management, Vol. 9 No. 2, pp. 215-237, doi: 10.1108/JM2-05-2012-0016.

Ponomarov, S.Y. and Holcomb, M.C. (2009), "Understanding the concept of supply chain resilience", The International Journal of Logistics Management, Vol. 20 No. 1, pp. 124-143, doi: 10.1108/ 09574090910954873.

Rahman, S.-U. (2006), "Quality management in logistics: an examination of industry practices", Supply Chain Management: An International Journal, Vol. 11 No. 3, pp. 233-240, doi: 10.1108/ 13598540610662130

Ralston, P.M., Keller, S.B. and Grawe, S.J. (2020), “Collaborative process competence as an enabler of supply chain collaboration in competitive environments and the impact on customer account management”, The International Journal of Logistics Management, Vol. 31 No. 4, pp. 905-929, doi: 10.1108/IJLM-11-2019-0310.

Richard, P.J., Devinney, T.M., Yip, G.S. and Johnson, G. (2009), "Measuring organizational performance: towards methodological best practice", Journal of Management, Vol. 35 No. 3, pp. 718-804, doi: 10.1177/0149206308330560.
Dynamic resilience capabilities 
IJLM 33,2

Rummel, R.J. (1970), Applied Factor Analysis, Northwestern University Press, Evanston, IL.

Schoenherr, T., Ellram, L.M. and Tate, W.L. (2015), "A note on the use of survey research firms to enable empirical data collection”, Journal of Business Logistics, Vol. 36 No. 3, pp. 288-300, doi: 10. $1111 / \mathrm{jbl} 12092$.

Scholten, K. and Schilder, S. (2015), "The role of collaboration in supply chain resilience”, Supply Chain Management, Vol. 20 No. 4, pp. 471-484, doi: 10.1108/SCM-11-2014-0386.

Sheffi, Y. and Rice, J.B. Jr (2005), "A supply chain view of the resilient enterprise”, MIT Sloan Management Review, Vol. 47 No. 1, pp. 41-48.

Shou, Y., Shao, J. and Chen, A. (2017), "Relational resources and performance of Chinese third-party logistics providers: the mediating role of innovation capability", International Journal of Physical Distribution and Logistics Management, Vol. 47 No. 9, pp. 864-883, doi: 10.1108/ IJPDLM-09-2016-0271.

Singh, S.K., Gupta, S., Busso, D. and Kamboj, S. (2021), "Top management knowledge value, knowledge sharing practices, open innovation and organizational performance", Journal of Business Research, Vol. 128, pp. 788-798, doi: 10.1016/j.jbusres.2019.04.040.

Sohn, J.-I., Woo, S.-H. and Kim, T.-W. (2017), "Assessment of logistics service quality using the Kano model in a logistics-triadic relationship", The International Journal of Logistics Management, Vol. 28 No. 2, pp. 680-698, doi: 10.1108/IJLM-09-2015-0172.

Soltani, E., Ahmed, P.K., Ying Liao, Y. and Anosike, P.U. (2014), "Qualitative middle-range research in operations management: the need for theory-driven empirical inquiry", International Journal of Operations and Production Management, Vol. 34 No. 8, pp. 1003-1027, doi: 10.1108/IJOPM-112012-0486.

Stank, T.P., Pellathy, D.A., In, J., Mollenkopf, D.A. and Bell, J.E. (2017), "New frontiers inlLogistics research: theorizing at the middle range", Journal of Business Logistics, Vol. 38 No. 1, pp. 6-17, doi: $10.1111 / \mathrm{jbl} .12151$.

Swanson, D., Goel, L., Francisco, K. and Stock, J. (2020), "Understanding the relationship between general and middle-range theorizing", The International Journal of Logistics Management, Vol. 31 No. 3, pp. 401-421, doi: 10.1108/IJLM-04-2019-0120.

Tabachnick, B.G. and Fidell, L.S. (2007), Using Multivariate Statistics, Allyn \& Bacon, Boston, MA.

Teece, D.J. and Pisano, E. (1998), "The dynamic capabilities of firms", in Dosi, G., Teece, D.J. and Chytry, J. (Eds), Technology, Organization, Competitiveness, Oxford University Press, Oxford, pp. 193-214.

Teece, D.J., Pisano, G. and Shuen, A. (1997), "Dynamic capabilities and strategic management", Strategic Management Journal, Vol. 18 No. 7, pp. 509-533.

Thai, V.V. (2013), "Logistics service quality: conceptual model and empirical evidence", International Journal of Logistics Research and Applications, Vol. 16 No. 2, pp. 114-131, doi: 10.1080/13675567. 2013.804907.

Tseng, P.-H. and Liao, C.-H. (2015), "Supply chain integration, information technology, market orientation and firm performance in container shipping firms", The International Journal of Logistics Management, Vol. 26 No. 1, pp. 82-106, doi: 10.1108/JJLM-09-2012-0088.

Thongkruer, P. and Wanarat, S. (2021), "Logistics service quality: where we are and where we go in the context of airline industry", Management Research Review, Vol. 44 No. 2, pp. 209-235, doi: 10.1108/MRR-12-2019-0544.

Tukamuhabwa, B.R., Stevenson, M., Busby, J. and Zorzini, M. (2015), "Supply chain resilience: definition, review and theoretical foundations for further study", International Journal of Production Research, Vol. 53 No. 18, pp. 5592-5623, doi: 10.1080/00207543.2015.1037934.

Wagner, S.M. and Kemmerling, R. (2010), "Handling nonresponse in logistics research", Journal of Business Logistics, Vol. 31 No. 2, pp. 357-381, doi: 10.1002/j.2158-1592.2010.tb00156.x. 
Wagner, S.M. and Sutter, R. (2012), "A qualitative investigation of innovation between third--party logistics providers and customers”, International Journal of Production Economics, Vol. 140 No. 2, pp. 944-958, doi: 10.1016/j.jpe.2012.07.018.

Wallenburg, C.M. and Schäffler, T. (2016), "Performance measurement in horizontal LSP cooperation as a field of conflict: the preventive role of collaborative processes", Logistics Research, Vol. 9 No. 7, pp. 1-7, doi: 10.1007/s12159-016-0134-y.

Wang, X., Yuen, K.F., Wong, Y.D. and Teo, C.-C. (2020a), "E-consumer adoption of innovative last-mile logistics services: a comparison of behavioural models", Total Quality Management and Business Excellence, Vol. 31 Nos 11-12, pp. 1381-1407, doi: 10.1080/14783363.2018.1485484.

Wang, M., Asian, S., Wood, L.C. and Wang, B. (2020b), "Logistics innovation capability and its impacts on the supply chain risks in the Industry 4.0 era", Modern Supply Chain Research and Applications, Vol. 2 No. 2, pp. 83-98, doi: 10.1108/MSCRA-07-2019-0015.

Wang, X., Wang, X. and Ran, L. (2020c), "Promoting synergistic innovation in logistics service outsourcing", Journal of Business and Industrial Marketing, Vol. 35 No. 6, pp. 1099-1112, doi: 10.1108/JBIM-08-2019-0385.

Wieland, A. and Wallenburg, C.M. (2012), "Dealing with supply chain risks linking risk management practices and strategies to performance", International Journal of Physical Distribution and Logistics Management, Vol. 42 No. 10, pp. 887-905, doi: 10.1108/09600031211281411.

Wong, C.W.Y. (2013), "Leveraging environmental information integration to enable environmental management capability and performance”, Journal of Supply Chain Management, Vol. 49 No. 2, pp. 114-136, doi: 10.1111/jscm.12005.

Xu, S., Zhang, X., Feng, L. and Yang, W. (2020), "Disruption risks in supply chain management: a literature review based on bibliometric analysis", International Journal of Production Research, Vol. 58 No. 11, pp. 3508-3526, doi: 10.1080/00207543.2020.1717011.

Yang, C.C. (2016), "Leveraging logistics learning capability to enable logistics service capabilities and performance for international distribution center operators in Taiwan", International Journal of Logistics Management, Vol. 27 No. 2, pp. 284-308, doi: 10.1108/IJLM-09-2014-0157.

Yang, C.-S. and Lirn, T.-C. (2017), "Revisiting the resource-based view on logistics performance in the shipping industry", International Journal of Physical Distribution and Logistics Management, Vol. 47 No. 9, pp. 884-905, doi: 10.1108/IJPDLM-05-2017-0184.
Dynamic resilience capabilities 
IJLM

33,2
518

\section{Appendix}

Measurement

scales

Median

SD

Organizational learning capacity (Lee and Song, 2015, p. 235; Yang, 2016, p. 307)

Cronbach's $\alpha=0.891$, AVE $=0.54, \mathrm{CR}=0.87$

How strongly do you agree with the following statement(s) about your firm's

Overall learning? My firm ...

LRC1 ... values new knowledge

0.808

LRC2 . . . distributes knowledge to all employees

2.0

1.059

LRC3 ... trains employees effectively

LRC4 ... values teamwork

LRC5 ... values cross-functional cooperation

LRC6 ... has a shared vision of purpose among its employees

1.039

0.731

$\begin{array}{ll}1.0 & 0.850\end{array}$

Collaboration (Shou et al., 2017, p. 871; Yang and Lirn, 2017, p. 904)

Cronbach's $\alpha=0.832$, AVE $=0.47, \mathrm{CR}=0.78$

How strongly do you agree with the following statement(s) about your firm's overall inter-firm relations? My firm ...

COLL1 ... values communication with business partners

COLL2 ... shares information with business partners

COLL3 ... views business partners as an extension of the firm

COLL $4 .$. values long-term relationships with business partners

$1.0 \quad 0.757$

$2.0 \quad 0.840$

$2.0 \quad 0.935$

$1.0 \quad 0.718$

Coopetition (Doz and Shuen, 1988; Fawcett et al., 2011; Mody, 1993; Teece et al., 1997)

Cronbach's $\alpha=0.933$, AVE $=0.81, \mathrm{CR}=0.93$

COOP1 . . collaborates with rivals

$3.0 \quad 1.146$

COOP2 ... learns from collaboration with rivals

COOP3 ... values collaborating with rivals

Innovation (Lee and Song, 2015 p. 235; Shou et al., 2017, p. 871; Yang, 2016, p. 307)

Cronbach's $\alpha=0.923$ AVE $=0.84, \mathrm{CR}=0.84$

How strongly do you agree with the following statements about your firm's overall innovativeness? My firm ...

INN1 . . . adopts new skills and technology

$2.0 \quad 1.085$

INN2 . . introduces new products or services

$2.0 \quad 1.070$

INN3 . . incorporates information about our industry, customers and competitors $\quad 2.0 \quad 1.022$

INN4 ... seeks creative solutions

$1.0 \quad 1.004$

INN5 ... seeks new ideas and opportunities

1.0

0.911

Robustness (Brandon-Jones et al., 2014, p. 64; Essuman et al., 2020, p. 6; Wieland and Wallenburg, 2012, p. 904)

Cronbach's $\alpha=0.873$, AVE $=0.49, \mathrm{CR}=0.82$

How strongly do you agree with the following statements about your firm's robustness during COVID-19? In comparison to its competitors, my firm. . .

RBT1 ... gave its employees enough time to consider a response

$2.0 \quad 0.977$

RBT2 ... carried out its normal functions despite some damage

2.0

RBT3 ... met operational needs despite some deviation

RBT4 ... performed well over a variety of scenarios despite some adaptations

2.0

0.986

RBT5 ... . reduced the impacts of the pandemic by responding effectively
RBons

0.969

$2.0 \quad 0.912$

Table A1.

Measurement scales

(continued) 
Measurement

scales

Median

SD

Dynamic recovery (Essuman et al., 2020, p. 6; Ponomarov and Holcomb, 2009; Tukamuhabwa et al., 2015)

Cronbach's $\alpha=0.863$, AVE $=0.49, \mathrm{CR}=0.82$

How strongly do you agree with the following statement(s) about your firm's recoverability since COVID-19? In comparison to its competitors, my firm. . .

SREC1 ... recovered to normal operations successfully

SREC2 ... recovered to normal operations quickly

SREC3 ... recovered to normal operations easily

DREC1 ... has developed new skills and capabilities

DREC2 . . has improved its market position

LSQ (Rahman, 2006, p. 235)

Cronbach's $\alpha=0.870$, AVE $=0.5, \mathrm{CR}=0.83$

How strongly do you agree with the following statements about your firm's LSQ since COVID-19? My firm . . .

LSQ1 ... has provided on-time delivery

LSQ2 . . has provided undamaged goods upon delivery

LSQ3 ... has provided error free transactions

$2.0 \quad 1.069$

$1.0 \quad 0.974$

LSQ4 ... has provided consistent order cycles

$2.0 \quad 0.952$

LSQ5 . . has provided total support of customer needs

Performance (Tseng and Liao, 2015, p. 93; Shou et al., 2017, p. 871)

How strongly do you agree with the following statements about your firm's performance since COVID-19? In comparison to its competitors, my firm ...

Cronbach's $\alpha=0.890, \mathrm{AVE}=0.39, \mathrm{CR}=0.75$

PERF1 . . has superior customer satisfaction $\quad 2.0 \quad 1.024$

$\begin{array}{lll}\text { PERF2 . . . has superior customer loyalty } & 2.0 & 0.973\end{array}$

$\begin{array}{lrr}\text { PERF3 . . . has a superior reputation } & 2.0 & 0.823\end{array}$

PERF4 ... has superior market share growth $\quad 2.0 \quad 1.065$

PERF5 ... has superior profitability $\quad 2.0 \quad 1.114$

Table A1.

\section{Corresponding author}

Irina Dovbischuk can be contacted at: dovbischuk@agkn.de

For instructions on how to order reprints of this article, please visit our website:

www.emeraldgrouppublishing.com/licensing/reprints.htm

Or contact us for further details: permissions@emeraldinsight.com 